\title{
A Review of Organotin Compounds: Chemistry and Applications
}

\author{
Duaa Ghazi, Zahraa Rasheed and Emad Yousif* \\ Department of Chemistry, College of Science, Al-Nahrain University, Baghdad, Iraq
}

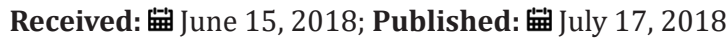

*Corresponding author: Emad Yousif, Department of Chemistry, College of Science, Al-Nahrain University, Baghdad, Iraq;

Email: emad_yousif@hotmail.com

\section{Historical Perspective}

The field of organotin chemistry has a long history that started since 1849, when Frankland isolated a specimen of diethyltin diiodide [1]. In 1852, Lowich reported on the reaction of alkyl halides with a tin-sodium alloy giving alkyltin compounds [2]. This last publication is usually considered to represent the beginning of organotin chemistry. By 1935, about hundreds of publications concerning organotin chemistry had appeared in the literature. At that time, important names had played a role in the development of organotin chemistry were Krause in Germany, Kraus in the United States, and Kozeshkov in Russia. The discovery of organotin compounds industrial applications as polyvinyl chloride (PVC) stabilizers, as agrochemicals, biocides, and wood preservatives produced a revival of organotin chemistry. Particularly van der Kerk and his co-workers in Netherlands played a major role in this development $[3,4]$. In early of 1960 s it was found that the tin atom in organ tin compounds is capable of extending its coordination number beyond four. Based on colligative studies, the trimethyltin chloride pyridine adduct, Figure 1, was the first documented fivecoordinate triorganotin halide complex that was proven by X-ray crystal structure [5]. Though divalent tin compounds had known for a long time, bis (cyclopentadienyl) tin (II) was the first example of a divalent organotin compound that was reported in 1956 [6].

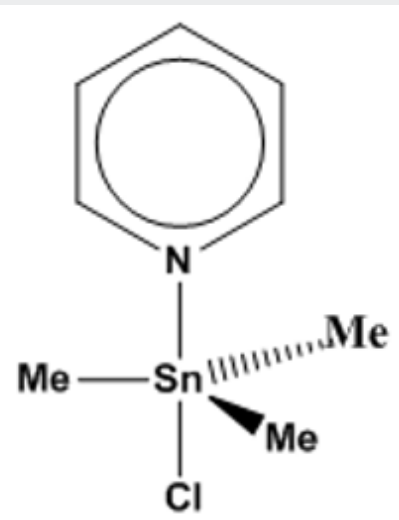

Figure 1: Trimethyltin chloride pyridine adduct.

\section{Industrial Preparation of Organotin Compounds}

On the industrial scale, organotin compounds are usually prepared by alkylation of $\mathrm{SnCl} 4$ with organo-magnesium or -aluminum compounds. Grignard reagents, RMgX, are prepared from the metal and an alkyl or aryl halide and need large volumes of solvent and are expensive. It is difficult to stop the reaction with SnCl4 to partial alkylation unless $\mathrm{R}$ is very bulky, and the reaction is usually taken to completion to give the product R4Sn, equations (1) and (2) [7].

$$
\begin{aligned}
& \mathrm{RX}+\mathrm{Mg} \stackrel{\mathrm{Et}_{2} \mathrm{O}}{\longrightarrow} \mathrm{RMgX} \\
& 4 \mathrm{RMgX}+\mathrm{SnCl}_{4} \longrightarrow \mathrm{R}_{4} \mathrm{Sn}+4 \mathrm{MgXCl}
\end{aligned}
$$

The tetraalkylstannane is then heated with the appropriate amount of $\mathrm{SnCl} 4$ (the Kocheshkov reaction) when redistribution occurs to give the alkyltin chlorides $\mathrm{R}_{\mathrm{n}} \mathrm{SnCl}_{4-\mathrm{n}}$ equation (3). Or scheme 1

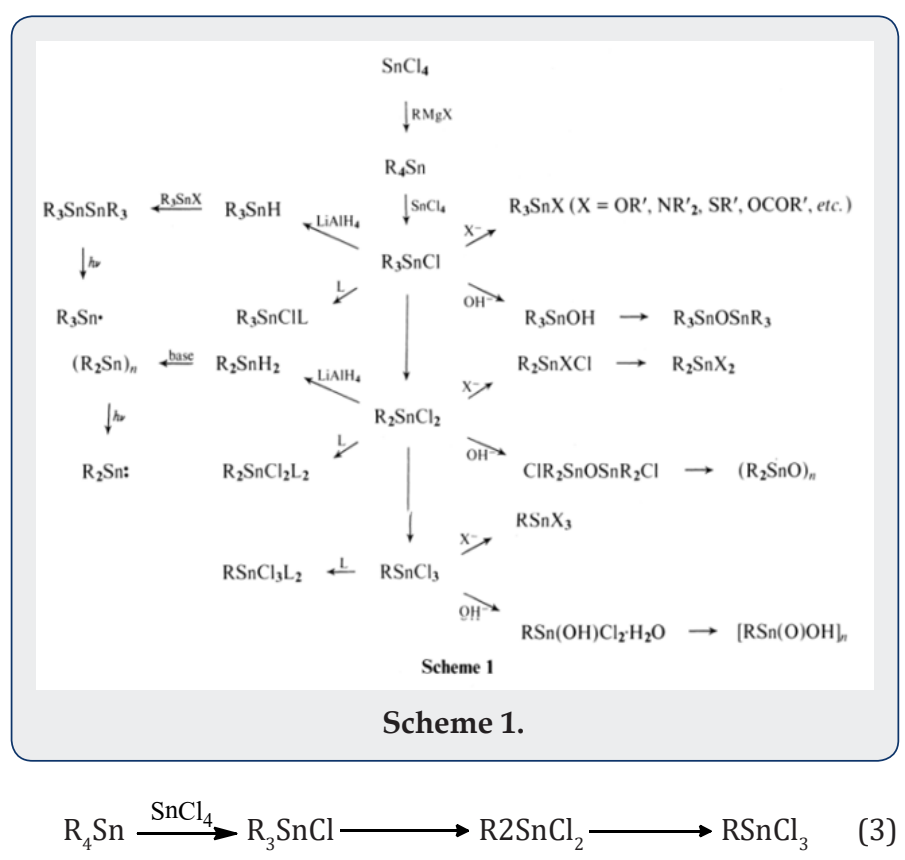


Usually in industry, the reaction is achieved with the low cost alkylaluminium compounds. Triethylaluminium can be made from aluminium metal, hydrogen and ethylene equation (4), and higher alkylaluminium compounds are then made between triethylaluminium and ethylene by the reaction of Ziegler growth, which needs no ethereal solvent equation (5). Trimethyl aluminium, which is strongly dimerised, does not give this reaction, so it is the even numbered alkylaluminium compounds, e.g. n-Bu3Al and (n-C8H17)3Al which are readily accessible.

$$
\mathrm{Al}+1.5 \mathrm{H}_{2}+\mathrm{CH}_{2}=\mathrm{CH}_{2} \stackrel{\mathrm{Et}_{3} \mathrm{Al}}{\longrightarrow} \mathrm{Et}_{3} \mathrm{Al}(4)
$$

$$
\mathrm{Et}_{3} \mathrm{Al}+3 \mathrm{nCH}_{2}=\mathrm{CH}_{2} \frac{110^{\circ} \mathrm{C}}{100 \mathrm{bar}}\left[\mathrm{Et}\left(\mathrm{CH}_{2} \mathrm{CH}_{2}\right)_{n}\right]_{3} \mathrm{Al}
$$

By reacting These organoaluminium compounds with $\mathrm{SnCl} 4$ to give the corresponding alkyltin chlorides, the syntheses are carried out with n-butyltin compounds, such as tri-n-butyltin hydride and di-n-butyltin dichloride, due to their low cost and less toxic compared to the methyltin compounds. Unlike Grignard reagents, these reactions can be taken to the stage of partial alkylation to give the alkyltin halides directly, e.g. equation (6). dibutyl- and dioctyltin dichloride are made industrially by this method.

$$
2 \mathrm{Bu}_{3} \mathrm{Al}+3 \mathrm{SnCl}_{4} \longrightarrow 3 \mathrm{Bu}_{2} \mathrm{SnCl}_{2}+2 \mathrm{AlCl}_{3}
$$

Other organotin derivatives can then be made from these chlorides. For example, treatment with sodium acetate gives the corresponding organotin acetates, and thiols under basic conditions give the tin thiolates, both of which are used as stabilizers for PVC. Progressive hydrolysis of dibutyltin dichloride gives first the dichlorodistannoxane which is used extensively as a catalyst and then dibutyltin oxide which is an insoluble polymer equation (7).

$$
\mathrm{Bu}_{2} \mathrm{SnCl}_{2} \stackrel{\mathrm{H}_{2} \mathrm{O}}{\longrightarrow} \mathrm{ClBu}_{2} \mathrm{SnOSnBu}_{2} \mathrm{Cl} \longrightarrow\left(\mathrm{Bu}_{2} \mathrm{SnO}\right)_{\mathrm{n}}
$$

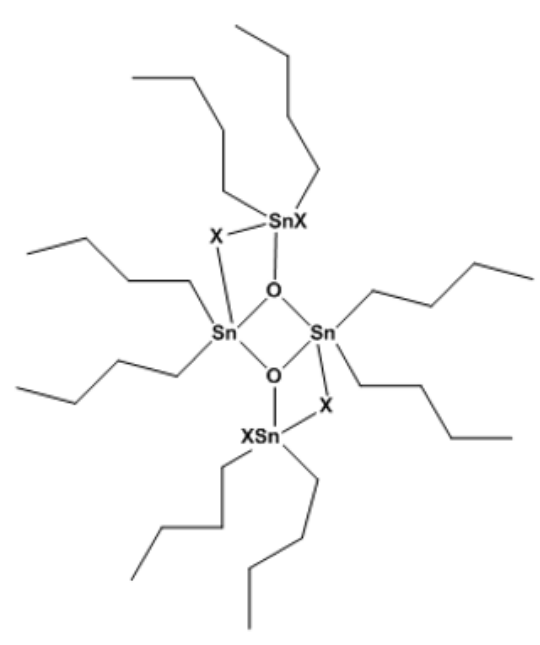

Figure 2: Difunctional distannoxanes.
These difunctional distannoxanes, XR2SnOSnR2X, are laddershaped dimers which are highly soluble in non-polar solvents because they have the structure of a reversed micelle Figure 2, with a polar core surrounded by lipophilic alkyl groups, and they are excellent catalysts for a number of organic reactions apparently because of their nature as binary Lewis acids [8]. Alternative method of forming the (Sn-C) bond was introduced in 1976 by the AKZO Company, which developed a series of PVC stabilizers (the Estertins), these are prepared by the reaction of $\mathrm{HCl}$ Gas with metallic tin or with $\mathrm{SnCl}_{2}$ in an ethereal solvent to give the solvated chlorotin hydrides $\mathrm{HSnCl} 3$ and $\mathrm{H} 2 \mathrm{SnCl} 2$, which add, in a heterolytic Michael fashion to acrylic esters to give $\beta$-alkoxycarbonylethyltin compounds equations (8) and (9). [8-10].

$$
\begin{aligned}
& \mathrm{Cl}_{3} \mathrm{SnH}+\mathrm{CH}_{2}=\mathrm{CHCO}_{2} \mathrm{R} \longrightarrow \mathrm{Cl}_{3} \mathrm{SnCH}_{2} \mathrm{CH}_{2} \mathrm{CO}_{2} \mathrm{R} \\
& \mathrm{Cl}_{2} \mathrm{SnH}_{2}+\mathrm{CH}_{2}=\mathrm{CHCO}_{2} \mathrm{R} \longrightarrow \mathrm{Cl}_{2} \mathrm{Sn}\left(\mathrm{CH}_{2} \mathrm{CH}_{2} \mathrm{CO}_{2} \mathrm{R}\right)_{2}
\end{aligned}
$$

The two reactions can be combined, as shown in equation (10) (Picture 1).

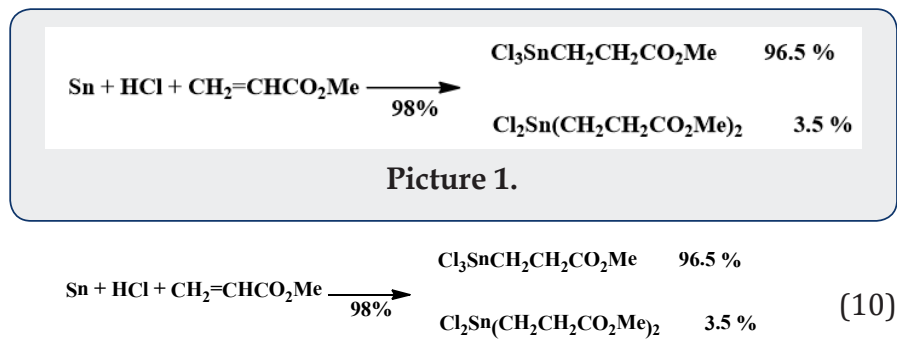

Extensive efforts have been made to prepare organotin compounds by the Direct reaction of metallic tin with organic halides, but the only process which as yet has been commercially successful is the preparation of dimethyltin dichloride from methyl chloride and tin in the presence of a catalyst equation (11) [11].

$2 \mathrm{MeCl}+\mathrm{Sn} \longrightarrow \mathrm{Me} 2 \mathrm{SnCl} 2$

\section{Tin Bonding and Valency}

In the periodic table of the elements, tin is listed in group 14, together with the elements carbon, silicon, germanium, and lead. Tin has two stable oxidation states, the Sn $(+2)$ and Sn (+4). For bonding The Sn $(+2)$ utilize the $5 p$ orbitals mainly and leaving the singlet unshared pair in the $5 \mathrm{~s}$ orbital with a little of $\mathrm{p}$ character, however, the organotin (II) compounds are not very stable, due to its tendency to polymerize rapidly and it can also be easily oxidized to the organotin (IV) which is the more stable. In the valence shell of the tin atom the four electrons have the $5 \mathrm{~s} 25 \mathrm{p} 2$ electronic arrangement that can undergo sp3 hybridization, and therefore tetravalent tin atoms are tetrahedral. The bonding of $\mathrm{Sn}$ is almost entirely covalent, at least in crystalline solids, in nonpolar solvents and in the vapor phase. This is true even for tin-halogen bonds. Within group 14, the bond lengths to carbon increase considerably: C-C 1.54, C-Si 1.94, C-Ge 1.99, C-Sn 2.15, and C-Pb 2.29 A $^{\circ}$. The 
increased bond length for tin is the cause of the increased reactivity and the related lower thermal stability of the tin alkyls compared with their $\mathrm{C}, \mathrm{Si}$, and $\mathrm{Ge}$ analogs. Long bonds naturally have low strength and lessen the screening of the central atom by the ligands. Attacking reagents thus have easier access. This is particularly evident in organo-lead compounds [5].

\section{Principal Coordination Geometries at the Tin Center in Organotin Compounds}

Before 1963, when Hulme used X-ray crystallography to demonstrate that the monopyridine adduct of trimethyltin chloride contains5-coordinate tin, it had been generally assumed that most organotin (IV) compounds are simple, tetrahedral molecules containing 4-coordinate tin atoms., however, the well-established techniques of proton NMR and infrared spectroscopy have been supplemented by 119Sn NMR spectroscopy [12,13], and these have stimulated X-ray investigations of a large number of organotin compounds, Many derivatives are now known that contain not only 5 and 6 but even 7 coordinate tin atoms [14]. The divalent as well as in tetravalent tin of empty $5 \mathrm{~d}$ orbital of suitable energy, it may be involved in the Hybridization, tin can have higher coordination numbers. In Figure 3, shows for both Sn (II) and Sn (IV) the principal coordination geometries, in the case of (II) tin, it is assumed that the lone pair is also participate in the hybridization. Some general trends for organotin coordination compounds have been well established. Based on the decreasing Lewis acidity with increasing number of organic groups present at tin, tetraorganotin compounds showed no capability to increase the coordination number due to the poor acceptor properties of the $\mathrm{Sn}$ in these compounds [15]. The preferred coordination geometry of the tin atom in triorganotin halides is trigonal bipyramidal, with the carbon of the ligand at the equatorial site and at the axial positions the donor atom and electronegative halide [16]. Both trigonal bipyramidal and octahedral coordination geometries have been found for the tin atom in adducts of diorganotin dihalides with Lewis bases. The solid-state structures of complexes, R2SnX2. 2L ( $\mathrm{L}=$ monobasic ligand), have generally two trans-oriented carbon ligands (R), whereas the two halide and the two donor molecules can adopt either mutual Trans or cis-configurations, depending upon the nature of the substituent [17]. In solution, these complexes exist in equilibrium of a hexacoordinate and a pentacoordinate species, with the latter as the predominant one [18] (Picture 2).
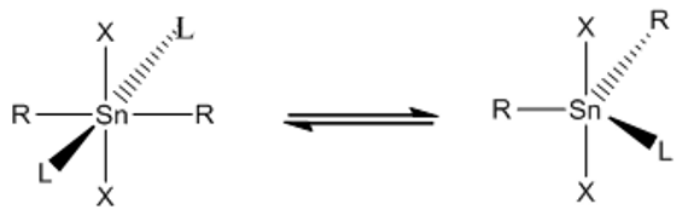

Picture 2.
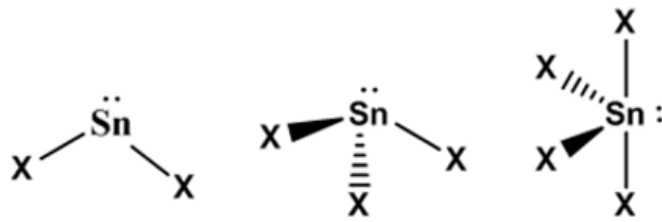

$1\left(\mathrm{sp}^{2}\right)$

$2\left(\mathrm{sp}^{3}\right)$

$3\left(\mathrm{sp}^{3} \mathrm{~d}\right)$

Structures of $\mathrm{Sn}(\mathrm{II})$ compounds.

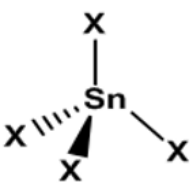

(4) $\mathrm{Sp}^{3}$

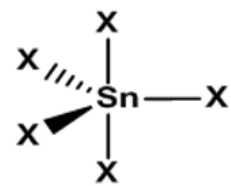

(5) $\mathrm{Sp}^{3} \mathrm{~d}$

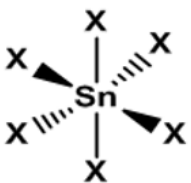

(6) $s p^{3} d^{2}$
Structures of Sn (IV) compounds.

Figure 3: The principal coordination geometries of divalent and tetravalent tin.

Monoorganotin compounds, RSnX, show a remarkable tendency to undergo to a higher coordination number to 5, 6 and7, and there are few Examples of compounds of the type RSnX which contain pentacoordinate tin. The anion in tetraphenylarsonium tetrachloromonomethylstannate, $(\mathrm{Ph} 4 \mathrm{As})+(\mathrm{MeSnCl} 2)-$, is one such example and consists of trigonal bipyramid and methyl group take an equatorial site [19]. A similar RSnX4, type of geometry was found in the intramolecular pentacoordinate, ketiminotin trichloride.

\section{Preview of Organotin Application}

In 1852 the synthesis of the first organotin compounds took place by Lowing and it was only after 80 years of the synthesis the organotins found application for transformer oils and vinyl plastics as stabilizers. Due to the development and increasing interest in the 1950s, significantly by Van der Kerk and co-workers, the organotin compounds commercial uses had expanded rapidly. There are three main areas of the utility of organotin compounds, as stabilizers of polymers, as industrial and agricultural biocides, and as catalytic agents in a many of chemical reactions.

\section{Stabilization of PVC}

Poly (vinyl chloride), PVC, is one of the most important commercial plastics, and its production is the third largest after polyethylene and polypropylene. It is used in many applications such as construction (window frames and water, sewage and drainage pipes), packaging (food and blood bags), household products (raincoats, toys, conduits and wall paper), decoration 
and wire coating [20]. Despite its appropriate properties, such as low cost, non-flammability and good versatility, its stability at elevated temperature and exposure to light is considered a serious environmental and health problem However, it is well known that
PVC degrades at these conditions, giving off successive hydrogen chloride gas (autocatalytic dehydrochlorination this progresses along the chain in a zipper fashion, to give an extended conjugated polyene (Picture 3).
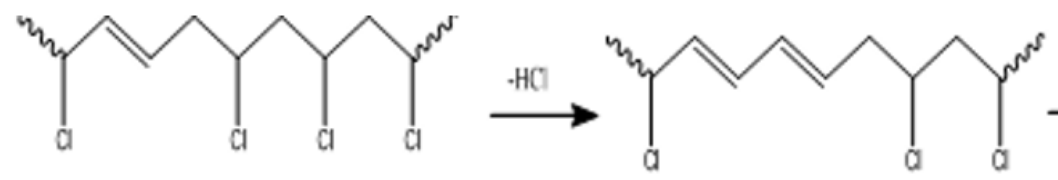
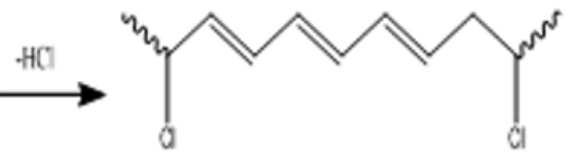

Picture 3.

The clear polymer develops a yellow, then brown, then black color, and it becomes brittle and insolubility of PVC with a decrease or an increase in molecular weight is due to the cross linking or chain scission of the polymer [21]. The initiation of PVC degradation is generally considered to be at the weak sites within the structure of the polymer such as branching, chloro-allyl groups, groups contain oxygen, structures of head to head and the monomer unit's stereo order (tacticity). However, stabilization of PVC against the degradation is essential for its processing and using [22].

Organotin compounds have been used as stabilizers to prevent this degradation since 1940 [23]. The first commercially successful stabilizers were dibutyltin dilaurate (4), dibutyltin maleate (5), and dibutyltin methyl maleate (6). Typically the loading of the stabilizer is $0.5-2 \%$ by weight of the polymer. With the optimum choice of organotin stabilizer stability is conferred on the PVC, both short term during processing, and subsequent long-term use, and the resulting polymer is clear and colorless. The primary mechanism of stabilization appears to be two-fold [24]. First, the organotin compound reacts at the allylic defect sites in the polymer, to replace $\mathrm{Cl}$ by an alkylthiyl group which is less prone to undergo elimination [equation (14)] (Picture 4).

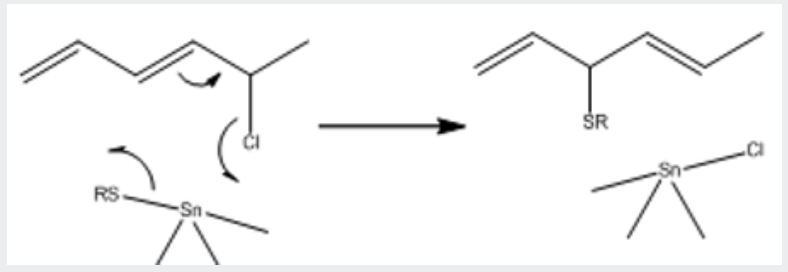

Picture 4.

The second effect is to remove the $\mathrm{HCl}$ [equation (15)] which otherwise catalyses the elimination [25] (Picture 5).

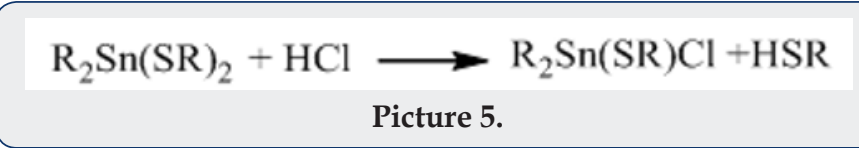

$$
\mathrm{R}_{2} \mathrm{Sn}_{(} \mathrm{SR}_{2}+\mathrm{HCl} \longrightarrow \mathrm{R}_{2} \mathrm{Sn}_{(} \mathrm{SR}_{)} \mathrm{Cl}+\mathrm{HSR}
$$

\section{Production of polyurethanes}

Polyurethanes (PUs) constitute one of the most important classes of polymeric materials with uses ranging from high performance structural applications to foam padding.1 Because of their diverse utility and relatively low cost, these materials account for nearly $5 \mathrm{wt} \%$ of total worldwide polymer production and are expected to exceed 18 kilotons annually by 2016 [26]. Based on the original discovery by Bayer, linear PUs is usually prepared by a straightforward route involving the reaction of diols with diisocyanates in the presence of a catalyst [27].

The enormous importance of the catalysts in PU chemistry is well recognized. Organotin compounds have predominantly filled this catalytic role. Two basic mechanisms have been proposed for the formation of the urethane linkage from the isocyanate and alcohol, involving either a direct insertion of the isocyanate into a Sn-O bond, or the organotin derivative acting as a Lewis acid [28]. They act as Lewis acids toward the polymerization with remarkable catalytic activity [29]. The mechanisms by which the tin compound operates as a Lewis acid are suggested to be important with the tin chlorides or carboxylates which do not readily exchange their ligands with the alcohol. Although their activation mechanism is still questioned, recent kinetic data suggest that the mechanism proposed by Bloodworth and Davies is the most likely [30]. The catalytic cycle involves the $\mathrm{N}$-coordination of the isocyanate with the tin alkoxide formed by alcoholysis of the starting tin compound, followed by transfer of the alkoxide anion onto the coordinated isocyanate to afford the $\mathrm{N}$-stannylurethane, which then undergoes alcoholysis to generate the targeted urethane and tin alkoxide.

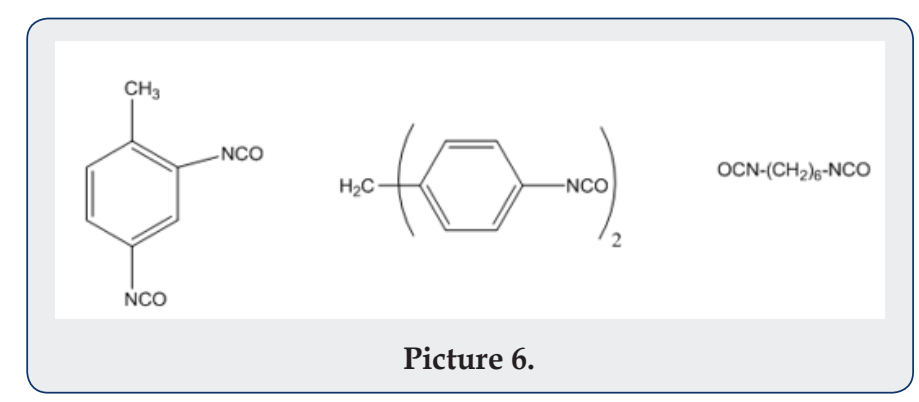


Typical isocyanates which are used are toluene 2,4-diisocyanate (1), bis(4-isocyanatophenyl) methane (2), and hexamethylene diisocyanate (3) (Picture 6).

The diols may typically be based on polyethylene oxide (4) or polypropylene oxide, or a diester-diol co-oligomer, e.g. (5) (Picture 7).

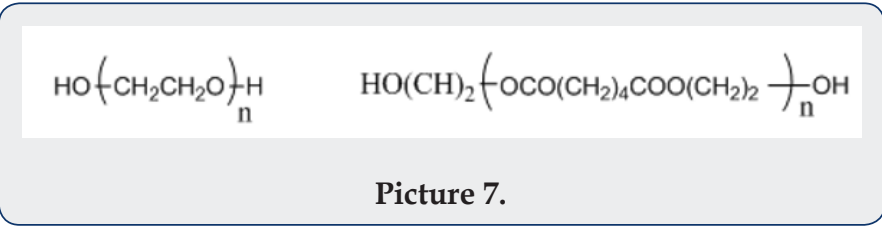

In catalyzing the chain extension reaction, the organotins appears to be most effective, so the chain extension and the gas formation reactions optimum rates of both achieved. The most commonly organotin catalysts used are dibutyltin diacetate, dibutyltin dilaurate, dibutyltin dilaurylmercaptide, dimethyl dichloride and dibutyltin dichloride.

\section{Room temperature vulcanisation of silicone polymers}

Silicone elastomers are widely used in many applications ranging from biomaterials [31]. To coatings and sealants, and so forth [32-34]. Although there are several methods available for their synthesis $[35,36]$. The most common of these are high-temperature radical cure, room-temperature vulcanization using either tin- or titanium-derived hydrolysis/condensation catalysts, or platinum- catalyzed hydrosilylation [37]. Polydimethylsiloxane is the most common siloxane polymer, that is formed when the hydrolysis of the chlorine of the monomer, dichlorodimethylsilane $(\mathrm{Cl} 2 \mathrm{Si}$ [CH3]2), replaced by hydroxyl $(\mathrm{OH})$ groups. The product is unstable compound, silanol ( $\mathrm{Cl} 2 \mathrm{Si}[\mathrm{OH}] 2)$,that goes on condensing in fashion of step-growth to form the polymer, with association of losing water. A cyclic product that are also formed, purify by distillation and by ring-opening polymerization convert to polysiloxane (Figure 4).

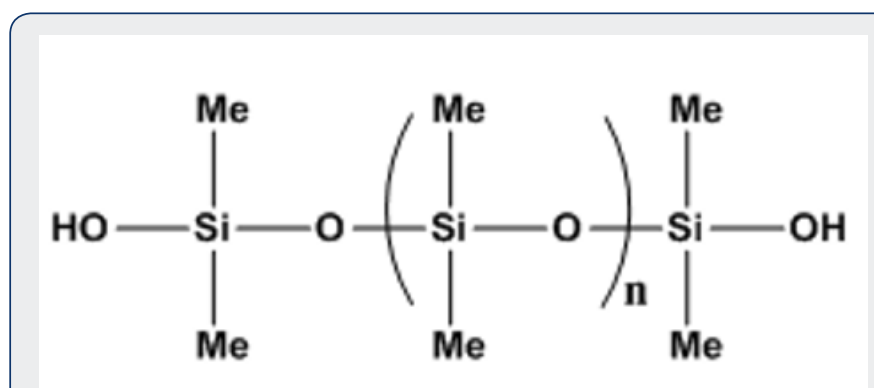

Figure 4: Polydimethylsiloxane.

The cross-linking of chains converts the silicone oils into elastomers with a wide variety of uses such as coatings, sealants, moulding compounds, release agents, encapsulants, and water repellents. This vulcanisation can be carried out at room temperature (room temperature vulcanisation, RTV) with a tri- or tetra-functional silane as a cross-linking agent and an organotin catalyst, which is commonly dibutyltin diacetate or dilaurate [equation (16)] (Picture 8).

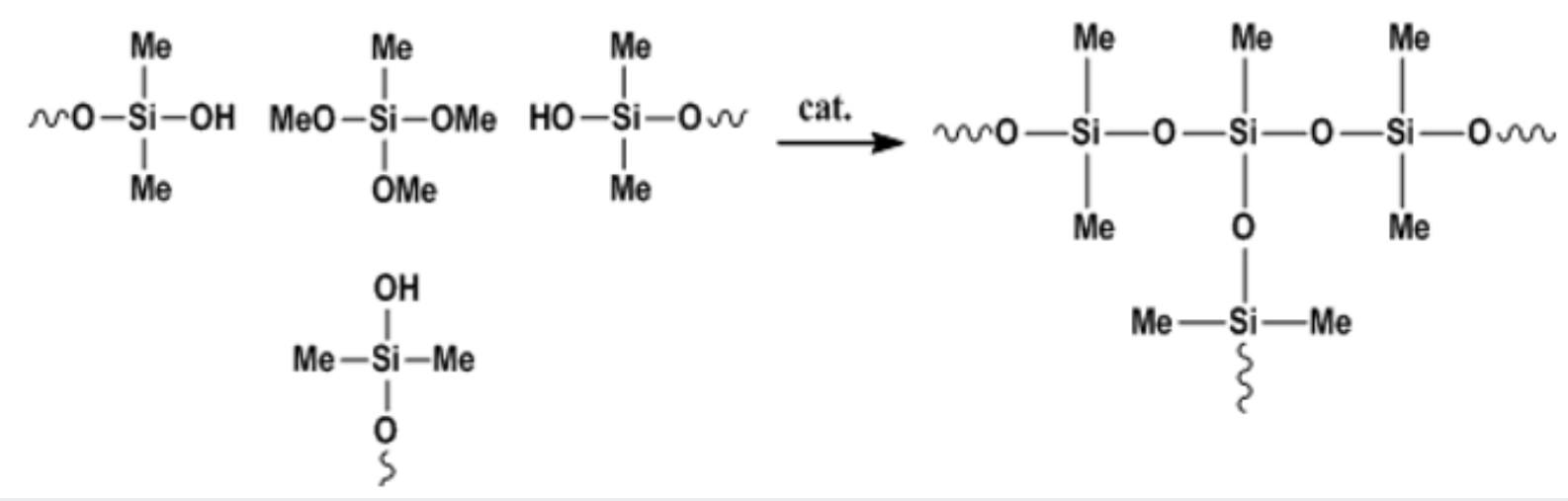

Picture 8.

The product may be supplied in two components, one consisting of the HO- terminal polysiloxane and the other containing the tri- or tetra-methoxysilane and the organotin catalyst, and reaction occurs when the components are mixed. A one-component product would contain a mixture of a MeO-terminal polysiloxane, the polyfunctional cross-linker, and the catalyst. When the mixture is exposed to air, the terminal $\mathrm{MeO}$ groups are hydrolysed to $\mathrm{OH}$, and vulcanisation takes place. A silanol-terminated silicone co-polymer can be crosslinked in the same way, and isocyanate-terminated polyurethanes can be end-capped with trialkoxysilyl groups and then subjected to vulcanisation, e.g. equation (17) [38] (Picture 9). The organotin dicarboxylate is first hydrolysed to the hydroxyl carboxylate. This reacts with the trialkoxysilane cross-linker to give a stannasiloxane, and this in turn reacts with terminal hydroxysilane groups of the polymer to cap it with a dimethoxysilane group. Repetition of this process gives a cross-linked polymer. 


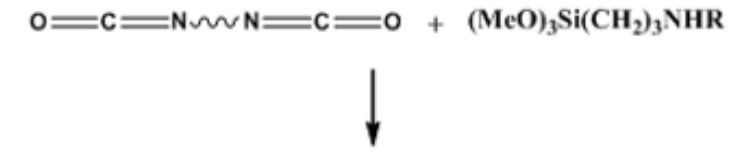

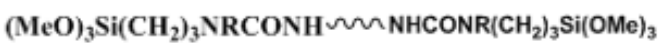

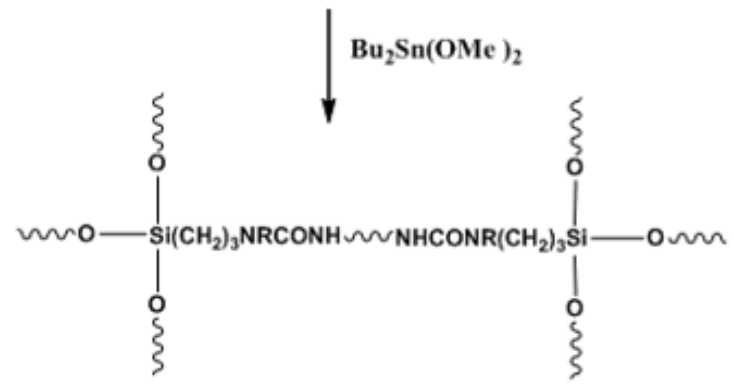

Picture 9.

\section{Transesterification and related reactions}

Reactions at carboxyl groups, such as esterification, transesterification, transcarbamolylation, lactonisation, and ring opening polymerization (ROP) are in important in chemical industry (Picture 10).

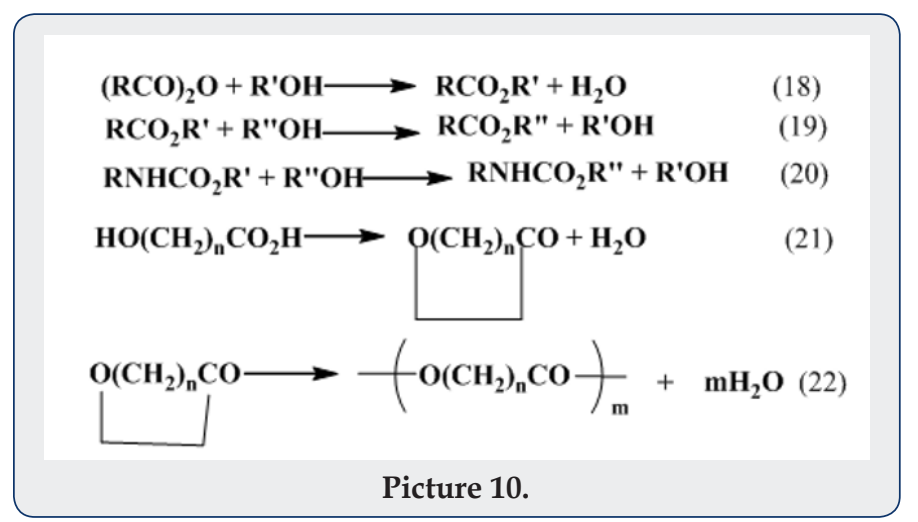

These reactions can generally be catalyzed by alkalis or protic acids, but frequently a less aggressive catalyst is needed because the reactants may be acid or base sensitive, or for avoiding corrosion of the plant, or for environmental reasons and organotin compounds are commonly used for this purpose. This is currently a very active field of study. Dibutyltin dilaurate and dibutyltin oxide are frequently used; the latter compound is an intractable polymer, but it dissolves on reaction with the carboxyl compound to give a distannoxane [39].

$$
2 \mathrm{Bu}_{2} \mathrm{SnO}+\mathrm{RCO}_{2} \mathrm{R}^{\prime} \longrightarrow \mathrm{RCO}_{2} \mathrm{Bu}_{2} \mathrm{SnOSnBu}_{2} \mathrm{OR}^{\prime}
$$

The outstanding advantages of the Organotin compounds as catalysts for esterification reactions, due to the catalytic with high efficiency, poor tendency to eliminate water to form olefins from secondary alcohols, the potency to produce colorless esters, and the imparting the heat of stabilization to condensation type polymers (polyesters), Also to improve the physical and electrical properties of the product

\section{Marine antifouling}

Antifouling paints had been used to prevent the growth of organisms 'fouling' such as seaweed, barnacles, and tubeworms which produce drag and drastically reduce the propulsion of the marine structures and vessels. The paints are directed to 'target' organisms that settle on solid surfaces after a period time in the sea. There are two distinguished forms of Antifouling paints- with or without TBT. There is a variety of alternative TBT-free paints [40]. In the 1960s, tributyltin and triphenyltin compounds (oxide, chloride, acetate, etc.) were introduced, replacing the copper oxide which had been used previously to reduce the growth of fouling. The organotin compound was incorporated into the hull paint ("free association paints"), and slowly diffused out, providing protection for 18-24 months. During that period, the rate of release declined as antifoulant had to diffuse to the surface from deeper in the paint [41].

There is a consequence of using the organotin as antifoulants that is their exceptional toxicity to marine organisms 'non-target'. In a diverse range of species, the organotin interfere with the biological processes. In the 1980s scientific evidence of worldwide demonstrated the extreme negative impacts on the marine environment by organotin compounds, TBT found in marinas with high concentrations and related to the growth with abnormalities in mussels and oysters and a decrease in their abundance. The use of these paints was progressively restricted in the 1980s due to its high toxicity on the marine environment, a ban on their use came into effect in January 2008 [42], but the technology that was developed is now being adapted to the design of self-polishing copper polyacrylates which work on the same principle.

\section{Wood protection}

Successful trials have been made in the preservation of various woods against insects, fungi, bacteria and wood-boring marine animals. Tributyltin (IV) complexes show effective biological activities against microorganism and are used for preservations of wood. An important properties of the organotin compounds is that they impart neither color nor odor to the treated wood. The treatment of wood with organotin (IV) compounds occur in a vacuum, into the wood the results released in a flow of the organotin (IV), which is attached with terminal $\mathrm{OH}$ groups of the cellulose to prevent the damage by microorganisms [43].

\section{Glass coating}

By using Atmospheric Pressure Chemical Vapor Deposition (APCVD) techniques to form electrically conductive thin films on the surface of glass by using Organotin (IV) [44]. Due to its wide range commercial applications and economical reason, as a precursor Tin 
chloride is used for the formation of transparent conductive oxide (TCO) films. Strength, thermal stability and resistance to oxidation are provided by the coating. TCO film also control the heat lossing through glass which is because of the deposition on glass surface by metal oxide film.

$$
\mathrm{SnCl}_{4}+2 \mathrm{H}_{2} \mathrm{O} \rightarrow \mathrm{SnO}_{2}+4 \mathrm{HCl}
$$

Using Tin Oxide for Coating glass have a different of important applications, Coated glass used in deicing wind shield screens, security glass, or display systems [45], due to their low electrical resistance and high resistance to chemicals. A layer $1-\mu \mathrm{m}$ thick can be used to fills in the imperfections in the of the glass surface so that thinner bottles can be used (e.g. milk bottles) which uses less glass and are bear to fewer breakages [46]. Coating can act as a p-type or n-type semiconductor or conductor. If doping the $\mathrm{SnO} 2$ with about $3 \%$ of fluoride makes it an n-type semi conductior; the filled and empty orbitals band gap is reduced into the infrared region, so that the glass becomes transparent to solar radiation, also reflective toward heat radiation. Doping with antimony and with indium is also common, though the latter (ITO, indium tin oxide) has a largely indium content. These semiconductors are used in a variety of electronic devices such as diodes, transistors, solar cells, heated windows, antistatic coatings, and sensors [47].

\section{Biological applications}

Organotin (IV) carboxylates uses for any specific biological activity is related to the nature and number of organic groups $\mathrm{R}$ directly which are attached to the tin atom and the carboxylate groups attached to the tin atom by $\mathrm{Sn}-\mathrm{O}$ bonds. The effectiveness of organotin (IV) compounds are decided by these factors for required purposes. The nature of the R group determines its site of attack for organotin (IV), binding to the different sites in the body, such as carbohydrates, nucleic acid derivatives, amino acids [48] and to proteins [49]. Hetero atoms presences such as $\mathrm{N}, \mathrm{O}$ or $\mathrm{S}$ in the ligand play a major role in the geometry and therefore affect the biological activity of these complexes [50]. The effective biological activity of organotin (IV) compounds motivate their applications in pharmaceutical.

\section{Pharmaceutical applications}

Metal ions have outstanding role in different physicochemical processes that take place in vivo and they are distinguished for their metallo pharmaceutical applications such as organotin (IV) compounds are used as effective biological agent against various diseases [51]. Study of organotin (IV) effectiveness and their mode of act by interaction with various parts like ATPase and hemoglobin's are studying model for interactions of drugs with the human body [52,53]. Attempts to develop new drugs for different purposes, synthesis of organotin (IV) complexes with new ligands and different coordination geometries are taken place. Applications in the fields of muoluscicides, veterinary science, antibacterial, antifungal, anti tumour, schizonticidal, antimalarial and amoebicidal agents are due to the potential biological activity of organotin (IV) complexes [54-68].

\section{Conclusion}

Organotin compounds find a bigger range of technological and industrial applications than the organic compounds of any other metal. Many of these applications involve catalysis or anti catalysis, often in polymer chemistry, and they have an importance out of all proportion to the tonnage of tin which is used. This article reviews the present standing of the biological applications of organostannanes, with an emphasis on the mechanisms of the reactions which are involved.

\section{Acknowledgment}

The project was supported by Al-Nahrain University.

\section{References}

1. Cochran J (1998) Book Review: Organotin Chemistry, Synthesis and Reactivity in Inorganic and Metal-Organic Chemistry 28(7): 1251-1252.

2. Shaib S, Shah A, Ashfaq M, Waseem A, Ahmed MM, et al. (2015) Synthesis and Biological Activities of Organotin (IV) Complexes as Antitumoral and Antimicrobial Agents. A review, Mini-reviews in medicinal chem 15(5): 406-426.

3. Van der Kerk GJM, Luijten JGA (1954) Investigations on Organo-Tin Compounds. III.The Biocidal Properties of Organo-Tin Compounds. J Appl Chem 4(6): 314-319.

4. Van der Kerk GJM, Luijten JGA, Noltes JG (1958) Neue Ergebniss der Organozinn- Forschung. Angew Chem 70(10): 298-306.

5. Hulme $R$ (1963) The Crystal and Molecular Structure of Chloro(trimethyl)-pyridinetin(IV). J Chem Soc pp. 1524-1527.

6. Fischer EO, Fritz HP (1959) Compounds of Aromatic Ring Systems and Metals. Advances in Inorganic Chemistry and Radiochemistry 1: 55-115.

7. Davies AG (2004) Organotin Chemistry $2^{\text {nd }}$ edn. Wiley-VCH, Weinheim.

8. Davies AG (2004) Difunctional distannoxanes, $\mathrm{XR}_{2} \mathrm{SnOSnR}_{2} \mathrm{X}$. J Chem Res 5: 309-314.

9. Buchanan H, Alan Howie R, Khan A, Spencer GM, Wardell JL, et al. (1996) Preparations and crystal structures of $\mathrm{Sn}\left(\mathrm{CH}_{2} \mathrm{CH}_{2} \mathrm{CO}_{2} \mathrm{Me}\right)_{2}\left(\mathrm{C}_{3} \mathrm{~S}_{5}\right)$ and [Q] $\left[\mathrm{Sn}\left(\mathrm{CH}_{2} \mathrm{CH}_{2} \mathrm{CO}_{2} \mathrm{Me}\right)\left(\mathrm{C}_{3} \mathrm{~S}_{5}\right)_{2}\right]\left(\mathrm{Q}=\mathrm{NEt}_{4}\right.$ or 1,4-dimethylpyridinium, $\mathrm{C}_{3} \mathrm{~S}_{5}=$ 4,5-disulfanyl-1,3-dithiole-2-thionate). J Chem Soc, Dalton Trans 0: 541548.

10. Hutton RE, Oakes V (1976) Organotin Compounds: New Chemistry and Applications, ed. J J Zuckerman (Ed). American Chemical Society 157: 123-133.

11. Burley JW, Hope P, Mack AG (1984) Synthesis of Ketoalkyltin Chlorides Via In-Situ Condensation and Hydrostannation of Ketonic Substrates. J Orgmetallic Chem 277(1): 37-46.

12. Roelens S, Taddei M (1985) Group 4 Organometallic Reagents. A ${ }^{1} \mathrm{H}$, ${ }^{13} \mathrm{C}$, and ${ }^{119} \mathrm{Sn}$ nuclear magnetic resonance study on 2,2-Dibutyl-1,3,2dioxastannolane Structure in Solution. J Chem Soc Perkin Trans 2(0): 799-804.

13. Meurice JC, Vallier M, Ratier M, Duboudin JG, Petraud M (1996) J Chem Soc Perkin Trans 2(0): 1311-1313.

14. Ho BYK, Zuckerman JJ (1973) Structure organotin chemistry. J Organornet Chem 49(1): 1-84.

15. Srivastav N, Singh R, Kaur V (2015) Carbastannatranes: powerful 
coupling mediators in Stille coupling, review article. RSC Adv 5: 6220262213.

16. Petrosyan VS, Reutov OA (1974) Study of the structure and complexation of organic and inorganic derivatives of metals by means of n.m.r. spectroscopy of heavy nuclei. Pure Appl Chem 37(1-2): 147-159.

17. Manders WF, Lockhart TP (1985) High resolution CPMAS ${ }^{13} \mathrm{C}$ NMR of Organometallic solids. Observation of J coupling to tin. J Orgmet Chem 297(2): 143-147.

18. Kabanos TA, Keramidas AD, Mentzafos D, Russo U, Terzis A, et al. (1992) Synthesis, structural and physical studies of tin(IV) complexes with 2-(2-pyridyl)benzimidazole. J Chem Soc, Dalton Trans 0(18): 27292733.

19. Shahzadi S, Ali S (2008) Structural chemistry of organotin (IV) complexes. J Iran Chem Soc 5(1): 16-28.

20. Ali M, El Hiti G, Ibraheem H, Yousif E (2017) Investigation of the Photodecomposition Rate Constant of Poly (Vinyl Chloride) Films Containing Organotin (IV) Complexes. J Al-Nahrain Uni 20(3): 18-23.

21. Tomi IH, Ali GQ Jawad AH, Yousif E (2017) Synthesis and characterization of gallic acid derivatives and their utilized as organic photo-stabilizers for poly (vinyl chloride). J Polym Res 24: 119.

22. Yousif E, Hasan A (2015) Photostabilization of Poly (vinyl chloride)-Still on the Run: A Review, J Taibah Uni Sci 9(4): 421-448.

23. Martins L, Hazra S, Silva M, Pombeiro (2016) A sulfonated Schiff Base Dimethyltin(IV) Coordination Polymer: Synthesis, Characterization and Application as a catalyst for Ultrasound- or Microwave-Assisted BaeyerVilliger Oxidation under solvent-free conditions. RSC Adv 6: 7822578233.

24. Poller RC (1978) Stabilization of PVC by Organotin Compounds. J Macromol Sci-Chem 12(3): 373-378.

25. Arkis E, Balkoese D (2005) Thermal stabilization of polyvinyl chloride by organotin compounds. Polym Degrad Stab 88(1): 46-51.

26. Chattopadhyay DK, Raju K (2007) Structural engineering of polyurethane coatings for high performance applications. Prog Polym Sci 32(3): 352 418.

27. Sardon H, Engler AC, Chan J, García J, Coady D, et al. (2013) Organic acid-catalyzed polyurethane formation via a dual-activated mechanism: Unexpected preference of Nactivation over 0-activation of isocyanates. J Am Chem Soc 135(43): 16235-16241.

28. Chattopadhyay DK, Webster DC (2009) Thermal stability and flame retardancy of polyurethanes. Prog Polym Sci 34(10): 1068-1133.

29. Devendra R, Edmonds NR, Söhnel T (2013) Computational and experimental investigations of the urethane formation mechanism in the presence of organotin (IV) carboxylate catalysts. J Mol Catal A: Chem 366(0): 126-139.

30. Bloodworth AJ, Davies AG (1965) Organometallic reactions. Part I. The addition of tin alkoxides to isocyanates. J Chem Soc pp. 5238-5244.

31. Mustoe T (2008) Evolution of Silicone Therapy and Mechanism of Action in Scar Management. Aesth Plast Surg 32(1): 82-92.

32. Chen H, Brook MA, Sheardown HD, Chen Y, Klenkler B (2006) Generic Bio affinity Silicone Surfaces. Bioconjugate Chem 17: 21-28.

33. Morgan J, Chen T, Hayes R, Dickie T, Urlich T, et al. (2017) Facile synthesis of dendron-branched silicone polymers. Polym Chem 8: 2743-2746.

34. Fawcett AS, Grande JB, Brook MA (2013) Rapid, Metal-Free Room Temperature Vulcanization Produces Silicone Elastomers. J Polym Sci A: Polym Chem 51(3): 644-652.

35. Liao X, Xu H, Shaojie L, Zhou C, Guangxian L, et al. (2015) The effects of viscoelastic properties on the cellular morphology of silicone rubber foams generated by supercritical carbon dioxide. RSC Adv 5: 106981106988.

36. Zhang M, Desai T, Ferrari M (1998) Proteins and cells on PEG immobilized silicone surfaces. Biomaterials 19(10): 953-960.

37. Clarson SJ (2003) Silicones and Silicone-Modified Materials: A Concise Overview. ACS Symposium Series 838: 1-10.

38. Yuan Y, Zhang Y, Fu X, Jiang L, Liu Z, et al. (2016) Silane-terminated polyurethane applied to a moisture-curable pressure-sensitive adhesive using tri ethoxysilane. RSC Adv 6: 83688-83696.

39. Otera J, Dan oh N, Nozaki H (1991) Novel TemplateEffects of Distannoxane Catalysts in Highly Efficient Transesterification and Esterification. J Org Chem 56(18): 5307-5311.

40. Piver WT (1973) Organotin Compounds: Industrial Applications and Biological Investigation. Environ Health Perspect 6: 61-79.

41. Omae I (2003) Organotin antifouling paints and their alternatives: A Review, App Organom Chem 17: 81-105.

42. Haruo M, Ryusei S, Yu S, Yuichi F, Akira T, et al. (2008) Accelerator Analysis of Tributyltin Adsorbed onto the surface of a Tributyltin Resistant Marine Pseudoalteromonas sp. Cell. Int J Mol Sci 9(10): 19892002.

43. Shiryaev V, Storozhenko P (2012) Application of organotin compounds for protecting wood and other materials and in nonfouling paints. Polymer Science Series 5(3): 221-230.

44. McCurdy R (1999) Successful implementation methods of atmospheric CVD on a glass manufacturing line. Thin Solid Films 351(1-2): 66-72.

45. Allendorf MD (2001) On-line Deposition of Oxides on Flat Glass. Electrochem Soc Interface: 34-38.

46. Tian JX, Zhang ZY, Yan JF, Ruan XF, Yun JN, et al. (2014) Hydrothermal synthesis and infrared emissivity property of flower-like $\mathrm{SnO}_{2}$ particles. AIP Adv 4: 1-8.

47. Jiang Y, Sun W, Yan M, Bahlawane N (2011) Application of ${ }^{n} \mathrm{Bu}_{2} \mathrm{Sn}(\mathrm{acac})_{2}$ for the deposition of nanocrystallite $\mathrm{SnO}_{2}$ films: Nucleation, growth and physical properties. J Alloys Comp 509: 7798-7802.

48. Yousif E, Mehdi B, Yusop R, Salimon J, Salih N, et al. (2014) Synthesis, structure and antibacterial activity of some triorganotin(IV) complexes with a benzamidoalanine ligand. J Taibah Univ Sci 8(3): 276-281.

49. Lochhart T, Davidson F (1987) Methyltin(IV) Structure Determination by NMR. X-ray and NMR Structural Analyses of Three $\mathrm{Me}_{2} \mathrm{Sn}$ (chelate) Compounds Bearing Five-Membered Chelate Rings. Organomet 6(12): 2471-2478.

50. Ghazi D, Yousif E (2017) Design of organotin (IV) complexes derived from ciprofloxacin. Int J Res Eng Innov 1(4): 63-65.

51. Osada S, Nishikawa J, Nakanishi T, Tanaka K, Nishihara T (2005) Some organotin compounds enhance histone acetyltransferase activity. Toxicology Letters 155(2): 329-335.

52. Nath M, Jairath R, Eng G, SongX, Kumar A (2005) New organotin(IV) ascorbates: synthesis, spectral characterization, biological and potentionmetric studies. Spectrochimica Acta Part A: Molecular and Biomolecular Spectroscopy 61(1-2): 77-86.

53. Pagliarani A, Bandiera P, Ventrella V, Trombetti F, Pirini M, et al. (2006) Response to alkyltins of two Na+-dependent ATPase activities in Tapes philippinarum and Mytilus galloprovincialis. Toxicol in Vitro 20(7): 1145-1153.

54. Nath M, Pokharia S, Yadav R (2001) Organotin(IV) complexes of amino acids and peptides.Coordination. Chemistry Reviews 215(1): 99-149. 
55. Yosuif E, El Hiti G, Hussain Z, Altaie A (2015) Viscoelastic, Spectroscopic and Microscopic Study of the Photo Irradiation Effect on the stability of PVC in the Presence of Sulfamethoxazole Schiffs Bases. Polymers 7(11): 2190-2204.

56. Gassan A, El Hiti G, Tomi IH, Haddad R, Al Qaisi A, et al. (2016) Photostability and Performance of Polystyrene Films Containing 1,2,4-Triazole-3-thiol Ring System Schiff Bases. Molecules 21: 1-12.

57. Ahmed D, El Hiti G, Hameed A, Yousif E, Ahmed A (2017) New TetraSchiff Bases as Efficient Photostabilizers for Poly(vinyl chloride). Molecules 22(9): 1-16.

58. Farina Y, Graisa A, Yousif E (2009) Synthesis, Structure and biological Activity of some Diorganotin(IV) with Benzamidomethionine. Modern Applied Science 3(4): 215-218.

59. Yousif E, Adil H, Majeed A, Farina Y (2009) Synthesis, characterization and fungicidal activity of some diorganotin(IV) with 2-thioacetic-5phenyl-1,3,4-oxadiazole. J fundamental Sci 5(2): 94-98.

60. Najeeb D, Shalan N, Ibraheem H, Farina Y, Yousif E (2009) Synthesis and fungicidal activity of some diorganotin(IV) with benzamidocysteine. J Al-Nahrain Univ 12(1): 24-28.

61. Graisa A, Farina Y, Yousif E (2009) Organotin(IV) Derivatives of N-Tolym-methoxybenzohydroxamic Acid: Synthesis and Structural Elucidation. Int J Chem 1(2): 34-47.
62. Farina Y, Graisa A, Kassem M, Yousif E (2008) Preparation and Spectroscopic Studies of Diorganotin(IV) Complexes of N-Phenyl-mNitrobenzohydroxamic Acid. European J Sci Res 22: 602-607.

63. Yousif E, Farina Y, Khadum S, Graisa A (2009) Triorganotin(IV) of benzamidoglycin: Synthesis and fungicidal activity. Int J ChemTech Res 1(3): 789-792.

64. Yousif E, Farina Y, Graisa A (2008) Synthesis and Characterization of Some Diorganotin(IV) Complexes of Benzamidoacetic Acid. Australian J Basic App Sci 2(4): 900-903.

65. Yousif E, Adil H, Majeed A, Graisa A, Farina Y (2009) Structural and fungicidalactivity of somediorganotin(IV) with benzamidophenylalanine. ARPN J Engin App Sci 4(6): 39-42.

66. Areej H, Mohamad T, Saad E, Farina Y, Graisa A, et al. (2009) Synthesis and Characterization and Fungicidal Activity of Triorganotin(IV) With Benzamidomethionine. European J Sci Res 34(2): 212-217.

67. Farina Y, Graisa A, Yousif E, Kassim M (2009) Synthesis and Structure of Some Diorganotin(IV) with N-methyl-m-nitrobenzohydroxamic Acid. Australian J Basic App Sci 3(1): 291-294.

68. Farina Y, Adil H, Ahmed A, Graisa A, Yousif E (2009) Synthesis, Structural and Fungicidal Studies of some Diorganotin (IV) with Benzamidoleucine. Australian J Basic App Sci 3(3): 1670-1673.
To Submit Your Article Click Here:

This work is licensed under Creative Commons Attribution 4.0 License

DOI: 10.32474/AOICS.2018.03.000161

\section{AOICS}

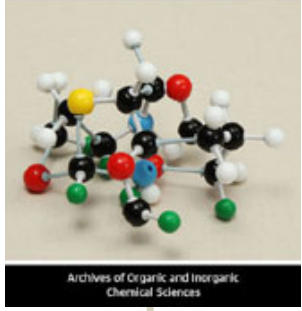

Archives of Organic and Inorganic Chemical Sciences

\section{Assets of Publishing with us}

- Global archiving of articles

- Immediate, unrestricted online access

- Rigorous Peer Review Process

- Authors Retain Copyrights

- Unique DOI for all articles 